\title{
Chapter 3: Linking Life Sciences with Disarmament in Switzerland
}

\author{
FRANÇOIS GARRAUX
}

\section{Introduction}

For the past few decades, the accelerated development of possibilities in engineering biological agents for specific purposes, as well as the possibility of using them with both peaceful and hostile intent, have posed fundamental challenges to security concepts at both national and international levels. In particular, the recent shift of emphasis in the nature of conflicts and the actors involved poses a challenge. Nowadays, not only states but also non-state actors are known to occasionally enforce their interests violently by the use of arms. The malevolent use of biological agents is not excluded, even though the number of occasions of real use by non-state actors remains limited. ${ }^{1}$ Closely related to this shift, the sophistication of possible means for transporting and spreading biological agents poses a challenge. Although their weaponisation remains a particularly demanding task, the possibilities to offensively spread pathogens nowadays go well beyond traditional military weapons and munitions - as the appearance of letters filled with anthrax spores in the US illustrated in $2001 .^{2}$ In additional, challenges are posed by the genuine dual-use character of a vast number of products that derive from life-science discoveries in general and results in biological and medical research in particular. ${ }^{3}$ Finally, these challenges are emphasised by the rapidly increased interconnection of our world ('globalisation'), resulting, amongst other things, in an almost-unlimited availability of products and information, but also in the facilitated and accelerated spread of diseases — SARS and the influenza viruses being prime examples. Such challenges open new fields and blur conceptual boundaries for

\footnotetext{
1 Jeanty, B. 2009, 'The biological weapons threat: The need for global prevention, preparedness, and response', Master Thesis, Swiss Federal Institute of Technology, Zurich, pp. 17-22.

2 Ibid. pp. 21-2.

3 Selgelid, M. and Weir, L. 2010, 'The mousepox experience. An interview with Ronald Jackson and Ian Ramshaw on dual-use research', European Molecular Biology Organization EMBO reports, vol. 11(1), p. 18.
} 
international, national and human security. They demand new assessments of threats and their origins, and ultimately call for new or additional approaches when developing strategies to respond and ensure security. Also, the international disarmament community faces the pressure to open up from the traditional state-military focus, to address diverse aspects of civil life, and develop novel measures to minimise potential security risks. ${ }^{4}$ When it comes to weapons of mass destruction in general and biological weapons in particular, the debates in recent years have increasingly focused on research by life scientists. Such debates have usually taken place in the context of 'dual use', a term that offers numerous definitions. In the framework of arms control, disarmament and the non-proliferation of weapons of mass destruction, 'dual use' is usually defined as the possibility that knowledge, facilities and technologies associated with civil applications may be used for the development, production, use or enhancement of military capabilities. ${ }^{5}$ Anne-Charlotte Merrell Wetterwik's example of the use of sophisticated ventilation filters in a pharmaceutical laboratory for the production of a biological weapon illustrates this definition. ${ }^{6}$ Awareness-raising and education, particularly on the potential misuse of originally well-intended research results and infrastructure, have thus been repeatedly mentioned as possible preventative measures.

In the context of its disarmament policy, the Swiss government has for years closely followed the debates on dual-use threats as well as related debates on contemporary security issues. It tries to apply the conclusions in a continuous national implementation of the Biological and Toxin Weapons Convention $(\mathrm{BTWC})^{7}$ and the development of security concepts. The national implementation of the BTWC, as Article IV of the Convention stipulates, also requests the prohibition and prevention of 'the development, production, stockpiling, acquisition, or retention of the agents, toxins, weapons, equipment and means of delivery specified in article I of the Convention, within the territory of such State, under its jurisdiction or under its control anywhere' ${ }^{8}$ A modern

\footnotetext{
4 A very concise introduction to the recent developments in disarmament and the need for new perspectives is given in Borrie, J. and Thornton, A. 2008, The value of diversity in multilateral disarmament work, New York and Geneva: UNIDIR.

5 Bonin, S. 2007, International Biodefense Handbook 2007. An inventory of national and international biodefense practices and policies, Crisis and Risk Network Series, Zurich: Center for Security Studies, p. 390; Resnik, D. 2009, 'What is "dual use" research? A response to Miller and Selgelid', Science and Engineering Ethics, vol. 15, pp. 3-5; Walker, J. 2003, 'Strengthening the BTWC. The role of the Biological and Toxin Weapons Convention in combating natural and deliberate disease outbreaks', European Molecular Biology Organization EMBO reports, vol. 4, special issue, pp. 61-5.

6 Merrell Wetterwik, A. C. 2009, 'Curbing illicit brokering in WMD-related items: solutions in the making', Disarmament Forum, vol. 3, p. 17.

7 The full title being 'Convention on the Prohibition of the Development, Production and Stockpiling of Bacteriological (Biological) and Toxin Weapons and on Their Destruction', as signed at London, Moscow and Washington on 10 April 1972, and entered into force on 26 March 1975, available: http://www.unog.ch/bwc [viewed 15 January 2010].

8 Ibid. Article IV.
} 
interpretation of this prohibition does not limit itself to a ban on 'classical' biological weapons in the sense of those intended for military use. Rather, it also addresses the activities of non-state actors in grey areas, and refers to the general availability of know-how and technology from life-science research that could be misused.

Based on this understanding, in the last few years government authorities have begun to focus on the extent to which researchers in Switzerland are aware of possible dual uses and this has led to a repeated outreach to academic institutions and the industry. The following chapter is an attempt to write a Werkstattbericht, a report on work in progress, on the introduction of educational aspects into national implementation measures in Switzerland's disarmament policy. Taking a government perspective, the report first sketches the relevant conditions for such an initiative, focusing on the educational framework, awareness, and national nuclear, biological and chemical (NBC) protection. It then highlights the preparation and implementation of, and lessons learned from, an awareness project carried out in 2009 by Professor Malcolm Dando (University of Bradford) and Dr. Brian Rappert (University of Exeter) and accompanied by the Swiss government. ${ }^{9}$ Provisional thoughts on possible further steps by authorities complement this part. Finally, some concluding remarks provide tentative thoughts in the wider context, encouraging the further development of a link between life scientists and practitioners in security and disarmament.

\section{Education and NBC Protection in Switzerland}

\section{Education and Awareness at Universities and in the Private Sector}

In line with Switzerland's federal structure, the Swiss system of public higher education is characterised by a complex system of shared competences between the Swiss Confederation (national level) and the cantons (sub-national level). The Swiss Confederation, namely the Federal Department for Home Affairs and the Federal Department for Economic Affairs, oversees the institutions of higher education mainly on policy and legal aspects, and shares the main responsibility for the general promotion of research. Here, the State Secretariat for Education and Research (SER) in the Federal Department of Home Affairs also focuses on national and international matters of university education, while the Swiss

9 For a detailed description of the seminar format and organisation, see Rappert, B. 2007, Biotechnology, security and the search for limits: An inquiry into research and methods, London: Palgrave; and Rappert, B. 2009, Experimental secrets: International security, codes, and the future of research, New York: University Press of America. 
Science and Technology Council acts as a consulting body for policy matters on education. However, the direct influence of the Confederation on the rules and regulations of specific institutions is limited to the two Swiss Federal Institutes of Technology (Zurich and Lausanne) and to four federal research institutes. ${ }^{10}$ In contrast, the cantons share the main responsibility for the universities, universities of applied sciences and further-education organisations. The cantons contribute substantially to the funding of the universities and have regulatory powers. Cantonal interests in university politics are coordinated through the Swiss University Conference, which simultaneously serves as the main platform linking the cantonal level and the Confederation.

This system of shared competences and different responsibilities, however, does not include a direct influence of government authorities on specific curricula; rather, it explicitly excludes it. Within the defined legal framework regulating predominantly administrative, organisational and financial matters, universities in Switzerland enjoy considerable academic autonomy and freedom of research and teaching. ${ }^{11}$ This autonomy also applies to research establishments within or connected to universities and the institutes of technology, even if they are primarily financed through public funds.

Besides research carried out in institutions of public higher education, lifesciences research conducted by the private sector plays an important role. As the pharmaceutical and chemical industries in Switzerland are among the most important economic sectors, specific research becomes vital for private enterprises and is actively supported. The Novartis Research Foundation or Roche's research and development activities may serve as prime examples. ${ }^{12}$ Research results originating from, as well as education within, the industry's development laboratories are primarily meant to meet the requirements of contemporary medicine and healthcare. In addition, they are subject to the economic imperatives the respective company faces in national and international markets. Therefore, a direct influence of government authorities on education and research in the private sector is practically impossible (and would be met with substantial mistrust and resistance), as long as education and research are completed within the existing legal framework.

10 State Secretariat for Education and Research SER 2008, The Swiss system of higher education (Factsheet), available: http://www.sbf.admin.ch/htm/dokumentation/publikationen/grundlagen/factsheets/FS01_ Hochschulsystem_e_2008.pdf [viewed 8 October 2009]; further information can be gathered from The Swiss Education Server Educa 2010, Universities, available: http://www.educa.ch/dyn/152941.asp [13 January 2010].

11 The Swiss Education Server, op. cit.

12 Novartis 2010, Corporate Research, available: http://www.novartis.com/research/corporate/index.shtml [viewed 13 January 2010]; Roche 2010, Research \& Development, available: http://www.roche.com/research_ and_development.htm [viewed 13 January 2010]. 
However, the (deliberate) lack of a government influence on the subjects taught does not automatically lead to the complete absence of concerns about misuse of life sciences. Traces of such concerns among academic circles at least implicitly exist. As far as university education is concerned, it remains unclear whether any academic course broaches the topic of dual-use research and related security implications. The following discussion of the awareness-raising project carried out in 2009 highlights findings that indicate an almost complete absence of this topic in regular life-sciences curricula. Nevertheless, a short examination of various curricula reveals that there are several academic courses touching upon this issue, particularly in the field of biomedical ethics. Yet these courses appear to focus on ethical questions for future physicians, or else highlight legal aspects. At best, (bio)security implications and consequences for the daily work in laboratories seem to be placed on the sidelines. ${ }^{13}$

As far as practitioners in academic or industrial laboratories are concerned, Swiss laws oblige these institutions to assign a person with sufficient professional background to oversee biological safety. In contrast, details concerning an appropriate education and training in biosafety are not regulated. ${ }^{14}$ This certainly confirms an awareness of biosafety in laboratories, but leaves specific questions on the knowledge of biosecurity open. (The ambiguous translation of 'safety' and 'security' into the official languages contributes to this apparently absent distinction. Both 'safety' and 'security' are translated into Sicherheit in German, sécurité in French, and sicurezza in Italian. ${ }^{15}$ ) Also, until relatively recently government support activities for biosafety officers were limited to very informal one-day seminars conducted by the Federal Office of Environment, the Swiss Expert Committee for Biological Safety and the Federal Office of Public Health. Only in 2008 did the government initiate and fund a Biosafety Curriculum for practitioners of the public and private sector, which will be discussed later. ${ }^{16}$

\section{NBC/CBRN Protection in Switzerland}

An examination of the national 'Swiss NBC-Protection Strategy'17 indirectly confirms these preliminary findings. The federal structure of Switzerland is

\footnotetext{
13 See for example the information provided by University of Basle 2010, Fachbereich Medizin und Gesundheitsethik (German), available: http://medethik.unibas.ch [viewed 13 January 2010]; University of Zurich 2010, Institute of Biomedical Ethics, available: http://www.ethik.uzh.ch/ibme_en.html [viewed 13 January 2010].

14 Streuli, J. 2008, 'Biosafety and Biosecurity Concepts', Statement of Switzerland at the BWC Meeting of Experts, 19 August 2008, available: http://www.unog.ch/bwc [viewed 9 November 2009].

15 For a discussion of this problem of terminology elsewhere, see Sawaya, D. 2009, 'Biosecurity at the OECD', in Rappert, B. and Gould, C. (eds.) Biosecurity: Origins, transformations and practices, London: Palgrave.

16 Streuli, J. op. cit.

17 Eidgenössische Kommission für ABC-Schutz (2007) Strategie „ABC-Schutz Schweiz“, available: http:// www.bevoelkerungsschutz.admin.ch/internet/bs/de/home/themen/abcschutz/strategie.html [viewed 14
} 
also mirrored in the authorities' approach to assess, prevent and respond to biological threats, together with chemical, radiological and nuclear risks. A complex web of cooperation among the Federal Office of Public Health, the Federal Commission for NBC Protection, the Federal Office for Civil Protection, the National Emergency Operations Centre, the Spiez Laboratory, the Swiss Armed Forces' NBC Centre of Competence, and the Armed Forces' Coordinated Medical Service characterises the approach on the national level. Again, these institutions closely cooperate with the cantons and municipalities, which are mainly in charge of the deployment of sensors and first responders such as police, fireguards, and first-aid providers. ${ }^{18}$ This broad variety of actors at national and sub-national levels can create (and has created) difficulties, often based on mutual misconceptions about their respective roles, unclear tasks and redundant structures. ${ }^{19}$ The NBC-Protection Strategy addresses these challenges and serves as a common base and guideline for prevention, intervention and coordinated leadership. It highlights the strengths and weaknesses of the current system and lists recommendations for improvement. When focusing on prevention, the strategy recommends an evaluation of existing NBC security laws, an assessment of the Confederation's and the cantons' approach to risk management (based on 14 scenarios, as set out in the annex to the strategy), and the establishment of a National NBC Protection and Coordination Office and a coordination platform for cantons. ${ }^{20}$

This focus on authorities and first responders illustrates that the national strategy is based on a well-developed awareness of threats originating from the accidental or deliberate release of biological agents, and the resulting ramifications for international, national and human security. However, the strategy bears the characteristics of a risk-management tool among authorities in a federal state, and does not serve as a comprehensive policy paper. Only the inclusion of the Spiez Laboratory indicates a potential and indirect link to academic and industrial life-science practitioners. Therefore, 'education' in the context of national strategy has little to do with a preventative awareness-raising among students, but is understood as being training in crisis management for responsible authorities.

\section{Preliminary Conclusion: The Missing Link}

The short elaboration on the system of public higher education in Switzerland describes an environment in which the formation of future life-science practitioners enjoys considerable academic freedom and is faced with few top-

January 2010].

18 Jeanty, B. op. cit. pp. 61-2.

19 Ibid. pp. 112-5.

20 Eidgenössische Kommission für ABC-Schutz, op. cit. 
down approaches from government authorities on thematic aspects. Likewise, education and research in the private sector is guided predominantly by actual needs in medicine and healthcare, as well as by economic imperatives. It is noteworthy that neither of these educational environments shows signs of an enhanced interest in security issues, despite their proximity to the topic, the possible relevance of security concerns to them, and the academic freedom and resources at hand. On the other hand, this short analysis of the Swiss national NBC strategy indicates an immense awareness of biosecurity concerns among authorities. The preventative approach, however, focuses on government authorities and first responders, and includes few wider references to other prospective or active practitioners outside.

This seems to reveal a missing link between life-science practitioners on the one hand, and security practitioners on the other. In simple terms, there is a missing link between the graduate student of biology, and the military intelligence officer or fireguard. Both sides have difficulties imagining the perspectives and concerns of the other.

The Swiss government took these findings as a call for an initiative to bridge this gap. The publication of a brochure titled Biology for Peace - Preventing the Misuse of Life Sciences ${ }^{21}$ in 2008 constituted a first step towards addressing the low awareness of security concerns within academic circles. Even minimal knowledge of obligations and debates on security at international level in combination with an increased personal responsibility among life-science practitioners should reduce the possibility of a misuse of potentially dangerous biological agents. After the brochure's publication, the timely offer of an existing project addressing precisely the gap identified in Switzerland provided a good opportunity to develop a further step in this direction.

\section{Implementing 'Awareness Raising': The 'Life- Sciences, Security, and Dual-Use Research' Project}

\section{International Impulses}

The misuse of life sciences and the associated security issues are not new to the BTWC community. In September 2002, the International Committee of the Red Cross (ICRC) launched a public appeal on biotechnology, weapons and

\footnotetext{
21 The brochure is available on the website of the State Secretariat for Economic Affairs SECO: http://www.
} seco.admin.ch/dokumentation/publikation/00035/02291/index.html?lang=en [viewed 15 January 2010]. 
humanity, calling for a 'web of prevention' among academic circles to impede biotechnology being misused for hostile purposes. ${ }^{22}$ Despite the failure of the ICRC's appeal to generate concrete results among the BTWC community, it paved the way for the later examination of academic research perspectives within a disarmament forum. ${ }^{23}$ Similarly, the discussions on codes of conduct for life scientists were characterised by an interest in the misuse of life sciences. Yet, as Dando highlights, '[it] has so far been unclear...to what extent this interest in potential dual-use aspects of the life sciences has led to concrete measures, particularly concerning education' ${ }^{24}$ This is certainly true of Switzerland, as discussed above.

The most recent and probably major impulse for an active engagement with education in Switzerland was taken from the current Intersessional Process of the BTWC and the focus on biosafety and biosecurity, as well as oversight, education and awareness-raising by the States Parties, international organisations and non-governmental organisations in 2008. The substantial discussions during the experts' meeting in August 2008 provided a fruitful basis for an exchange between life scientists and the BTWC community on concrete measures. Based on its own recent experiences at a national level, the Swiss delegation observed that '[while] governments are best placed to create the framework required, the individual researchers and their scientific and professional associations also play a crucial role' ${ }^{25}$ This spirit of a mutual inclusion of perspectives as well as the need to encourage awareness within academic circles through active and preventative government initiatives also entered the Meeting of States Parties in December of the same year. The final document of the meeting states:

(26) States Parties recognized the importance of ensuring that those working in the biological sciences are aware of their obligations under the Convention and relevant national legislation and guidelines, have a clear understanding of the content, purpose and foreseeable social, environmental, health and security consequences of their activities, and are encouraged to take an active role in addressing the threats posed by the potential misuse of biological agents and toxins as weapons, including for bioterrorism. States Parties noted that formal requirements for seminars, modules or courses, including possible mandatory

22 ICRC (2010) Biotechnology, weapons and humanity, available: http://www.icrc.ch/Web/Eng/siteeng0.nsf/ htmlall/bwh?OpenDocument [viewed 12 January 2010].

23 Borrie and Thornton 2008, op. cit., pp. 58-60.

24 Dando, M. 2009, 'Dual-use education for life scientists?', Disarmament Forum, vol. 2 , p. 41.

25 Streuli 2008, op. cit. 
components, in relevant scientific and engineering training programmes and continuing professional education could assist in raising awareness and in implementing the Convention. ${ }^{26}$

This agreed language provided a useful backdrop for a follow-up to the publication of the aforementioned brochure. The Swiss government authorities directly involved in the BTWC process considered the proposal by Dando and Rappert to conduct a series of seminars on current debates on life sciences, security, and dual-use research as very timely and relevant.

\section{The National Legislation}

Regardless of the modalities of Switzerland's participation in a project, all activities of the government require the existence of a relevant legal base. Again, the federal structure of Switzerland is mirrored in its legal system, resulting in a patchwork of national and cantonal regulations. Switzerland identifies with the monist system and treaties such as the BTWC automatically become part of the domestic legal system. However, Switzerland does not have one, single, specific act implementing the BTWC's obligations. Instead, the Convention's obligations are implemented through the sum of numerous national and cantonal legal texts covering a large spectrum of aspects, which inter alia, also relate to specific obligations of the BTWC. ${ }^{27}$ Consequently, the legal base for the awarenessraising project could not be derived from a single act, but was provided by various legal foundations. In addition to the BTWC and the 2008 Report of the Meeting of States Parties, the following national laws also pertain here:

- Federal Act on Combating Communicable Human Diseases (Epidemics Act) $1970 .^{28}$ The Confederation and the cantons are obliged to implement all necessary measures to prevent and combat the transmission of such diseases. The act furthermore specifies certain containment measures and names the responsible authorities. The Federal Act on Animal Epidemics $1966^{29}$ and the Federal Act on Agriculture $1998^{30}$ address animal and plant aspects, respectively.

\footnotetext{
26 Meeting of the States Parties to the BTWC 2008, Report of the meeting of states parties (UN document $B W C / M S P / 2008 / 5)$, Geneva: United Nations, pp. 6-7.

27 For a detailed description of the relevant legal framework on the prevention and response to biological threats, see Guery, M. 2004, Biologischer Terrorismus in Bezug auf die Schweiz (Unter besonderer Berücksichtigung rechtlicher Aspekte), Zürcher Beiträge zur Sicherheitspolitik Nr. 74, Zurich: Center for Security Studies, pp. 102-14. A comprehensive list of BTWC-relevant legal texts was similarly collected in the context of a study by Scott Spence/VERTIC in relation to the implementation of the BTWC in Switzerland.

28 Swiss legislation number SR 818.101.

29 Swiss legislation number SR 916.40.

30 Swiss legislation number SR 910.1.
} 
- Federal Act on War Material (War Material Act) 1996 ${ }^{31}$ : Article 7 stipulates the comprehensive prohibition of the development, production, brokering and acquisition, and any kind of transfer of nuclear, biological or chemical weapons. Article 34 punishes offences committed wilfully or through negligence.

- Swiss Criminal Code of $1937:^{32}$ Article 231 punishes the transmission of a dangerous communicable human disease, whether the offence is committed wilfully or through negligence. Articles 232 to 234 equally punish the transmission of epizootic diseases, pests, and the contamination of drinking water.

- Federal Act on the Control of Dual-Use Goods and of Specific Military Goods (Goods Control Act) 1996: ${ }^{33}$ The act creates the base to implement international agreements on respective goods, and enhances international non-binding control measures through specific national control measures. It particularly introduces the obligation to license and report the research, production and storage, as well as the (international) transfer of, dual-use goods, and enables the authorities to punish offences.

- Federal Act on the Protection of the Environment (Environmental Protection Act) of 1983: ${ }^{34}$ Preventative measures must be taken to protect and preserve people, animals and plants as well as biological communities and habitats. Articles 29a to $29 \mathrm{~h}$ focus on handling organisms and regulate responsibilities, licensing and reporting for activities in contained areas or for experimental releases.

Taken together, the Swiss legislation related to the implementation of the BTWC gives a comprehensive legal base covering both civil and military aspects and actors. In this sense, it addresses the ambiguous nature of biological threats and occasionally focuses directly on dual-use goods. Also of particular interest is the repeated reference to acts committed through negligence, which delegates responsibility to individual researchers. In addition, the respective responsibilities and duties of the relevant authorities to prevent the spread of diseases are clearly defined (thus setting the base for the NBC-protection strategy discussed above). However, the act leaves enough room for further preventative measures by the Confederation or the cantons. Based on these findings, implementing an awareness-raising project was a logical next step from a legal perspective.

31 Swiss legislation number SR 514.51.

32 Swiss legislation number SR 311.0.

33 Swiss legislation number SR 946.202.

34 Swiss legislation number SR 814.01. 


\section{Preparation for the Project}

Whilst the Political Secretariat of the Federal Department of Foreign Affairs (FDFA) takes the lead regarding BTWC matters, the Federal Office of Public Health (FOPH), the State Secretariat for Economic Affairs (SECO), and various offices in the Federal Department of Defence, Civil Protection and Sport (DDPS) - including the Spiez Laboratory - contribute their expertise and participate in the decision-making processes. In late 2008, these offices jointly decided to implement the seminars in the 2009 calendar year as a next step in an emerging long-term outreach towards academic institutions.

Making use of the experience accumulated by Dando and Rappert in conducting seminars in various countries, and to minimise the authorities' influence on the content and approach, in January 2009 the Swiss authorities, in conjunction with the two researchers, defined the basis for the project, as follows:

- The target audience should primarily include graduate students, faculty staff, and practitioners. The format foresees an interactive seminar of roughly an hour and a half.

- With regard to the content and educational material, the responsibility for the implementation remains fully with the two researchers who will conduct the seminars.

- The budget to cover all of the researchers' expenses directly related to the seminars, including travel expenses, was provided by the Alfred P. Sloan Foundation.

- The Swiss authorities act primarily as door-openers, establishing the contact between the researchers and potentially interested institutions. After a first contact, details in administration and teaching would be directly organised between the two researchers and the respective institution. Thus the role of the authorities would be an accompanying one rather than a supporting one.

- The authorities will provide logistical support to the two researchers in Switzerland.

\section{Opening Doors}

The Arms Control and Disarmament Policy branch of the Federal Department of Defence provided the administrative support, sending out an introductory letter to potentially interested academic and research institutions in early 2009. Referring to the current debates on dual-use research and its security implications, the letter invited expressions of interest from academics in a free seminar on the topic, organised by the two researchers, and accompanied by representatives from the federal government. The institutions were only required to organise a suitable classroom, date and time. To avoid the time-consuming 
process approaching the universities' hierarchies, the introductory letter was specifically targeted to the relevant institutes or university departments. Research institutions in the private sector were addressed via their official contact details. Interested academics and practitioners were then invited to deal directly with Rappert for all further administrative details.

The response was mixed. From the 12 institutions approached, seven indicated some or great interest, and six (in alphabetical order below) then agreed to conduct the seminars:

- Friedrich Miescher Institute, Basle

- Spiez Laboratory

- Swiss Society for Microbiology

- University of Basle, Biozentrum (Department Biozentrum)

- University of Geneva, Section de Biologie

- University of Zurich, Institute of Molecular Biology

The other five institutions showed no interest, or left the introductory letter unanswered.

The seminars were held in the summer of 2009, taking place in very diverse settings, as the following brief chronological abstract highlights:

- 4 June 2009: Seminar on the occasion of the Annual Conference of the Swiss Society for Microbiology. Time constraints meant that the seminar was slotted in between two other presentations and was limited to just 30 minutes. The fact that there were only two participants also hampered the debate. This early experience revealed the need to address life scientists within their own environment, as discussed later.

- 23 June 2009: Seminar at the Section de Biologie, University of Geneva. Attended by more than two dozen students, the increasingly lively discussions indicated an interest in the topic.

- 20 August 2009 (am): Seminar at the Department Biozentrum, University of Basle. A lively discussion among some 50 participants made the seminar one of the most successful of the series.

- 20 August 2009 (pm): Seminar at the Friedrich Miescher Institute, Basle. Despite there being only five participants, the researchers and the accompanying government official were confronted with very critical questions, finally indicating a crucial divide between life-science practitioners and security practitioners in the assessment of biological threats and their origins.

- 21 August 2009 (am): Seminar at the Spiez Laboratory, followed by a trainthe-trainer session. The in-house seminar for an authority directly involved 
in the implementation of the BTWC and the national NBC protection allowed the participants to gather provisional conclusions for possible further steps.

- 21 August 2009 (pm): Seminar for the Institute of Molecular Biology, University of Zurich. The seminar's very active debates among approximately 30 participants indicated a substantial interest in the topic. This was followed by further questions from students after the session.

\section{The Seminar's Framework and Resulting Debates}

The fundamental issue for the seminar was the question of whether life scientists should publish research results (and to whom) if there was a potential danger that the results would attract the attention of those with dubious motives for wanting such information and (theoretically) provide them with know-how to develop biological pathogens for offensive purposes. This represents the reformulation of the crucial assessment by every scientist whether the value of a publication outweighs the potential risks. The seminar was not intended, however, to provide a definitive answer to the question but to stimulate debate and perhaps challenge existing opinions.

Dando kicked off the debate by summarising the mousepox experiment, about which very few of the participants had heard. In that experiment, researchers had genetically engineered a virus for pest-control purposes, but this ultimately resulted in the creation of a lethal virus that even killed vaccinated mice. In theory at least, this opened the possibility of genetically engineering a lethal human virus, against which vaccination would be ineffective. ${ }^{35}$ The seminar participants were asked whether, in such circumstances, they would publish the research result and how they would come to their decision. Based on the first responses, which usually supported the idea of publication, the angle was changed to highlight possible sequences in publishing the results in various scientific journals. This model of stimulating an open debate with questions was continuously applied throughout each seminar, with reference to recent developments in biotechnology as well as occasional responses by governments such as intensified biodefence programmes or tightened control over scientists.

The responses from participants were strikingly similar throughout the seminar series. A large number found themselves confronted with a new perspective on their work. In various after-class conversations, participants repeatedly admitted that they had never previously considered a potential misuse of their research. Despite this, the clear majority ultimately felt the value of a publication outweighed the potential risks, and justified their position in various ways. Some

35 Jackson, R. et al. 2001, 'Expression of mouse interleukin-4 by a recombinant ectromelia virus suppresses cytolytic lymphocyte responses and overcomes genetic resistance to mousepox', Journal of Virology, vol. 75(3), pp. 1205-10; cited in Selgelid and Weir 2010, op. cit., pp. 18-24. 
referred to publication as a basic professional requirement ('publish or perish'). Others were of the opinion that, sooner or later, potentially dangerous knowhow would be published in any case; if they did not publish it, someone else would. The prospect of a governmental top-down approach to regulate research publications was generally met with substantial scepticism. When asked about threats, the participants' description of potential dangers and possible actors with malign intent remained very vague most of the time. Few narrowed their answer to terrorists (namely Al-Qaeda), and only one or two mentioned states with extensive biodefence programmes. International regimes such as the BTWC or relevant national legislation were almost never referred to by (and were seemingly unknown to) the vast majority of participants. There were no further indications that contributors had reconsidered their research activities in light of national and/or human security prior to the seminars. Nevertheless, most participants repeatedly agreed that researchers in the life sciences share a moral responsibility; living this responsibility is, however, often limited by professional and economic imperatives.

\section{Analysis, Lessons Learned, and Possible Ways Forward}

\section{Addressing Existing Needs}

A provisional analysis seems to confirm a generally low awareness of the potential misuse of dual-use research within Swiss life-science research institutions. This manifests itself not only in a repeated unawareness of often-quoted research experiments among university students in particular, but also in a frequently diffuse or narrow assessment of potential dangers and actors. While the complete absence among life scientists of references to security policy or disarmament regimes is perhaps understandable, the lack of references to relevant acts in the national legislation is noteworthy. Nevertheless, the readiness of a number of institutions to implement the seminars and distribute the 'Biology for Peace' brochure, and the interest many participants showed, seems to verify that many life-science practitioners consider further thought on dual-use research, ethics, and (moral) responsibility by researchers to be important. The existence of several courses in biomedical ethics corroborates this trend. These findings lead to the conclusion that the government initiative to support debate on dual-use research and related security issues addresses existing needs. Moreover, further steps will be necessary if sustained awareness is to be generated.

However, the government will have to consider approaches that are not perceived as interference with the freedom of research or as an obstacle to economic 
independence. A direct top-down approach from national authorities on the curriculum of universities or enterprises would not only generate scepticism among practising life scientists, but would also stand in sharp contrast to the federal structures on which the Swiss educational and legal systems are based. Any further outreach initiatives will have to take into account existing patterns of shared competences and cooperation. For example, approaches that inform researchers on current debates on dual use and security during established courses, and convince them to introduce the topic into their daily environment, are more likely to succeed. Similarly, another promising method includes the sensitisation of first responders and security practitioners, encouraging them to address life scientists in the context of their daily professional activities and thus act as close and credible intermediaries.

\section{Lessons Learned}

Several points raised by Dando and Rappert during the train-the-trainer session in the Spiez Laboratory provide practical hints for possible further activities. Only a few institutions are likely to create new courses or lectures specifically on dual-use research and security. The authorities' initiatives are likely to generate sustainable solutions if incentives exist for the integration of the topic into current curricula. Such motivations could include elements or even ready-made packages of teaching material. In this context, the low attendance during the first seminar (and the speakers' experience elsewhere) confirms the necessity for addressing life scientists within their regular study and work environments, rather than trying to lure them to separate or peripheral events. This was borne out by the success of ensuing seminars that were held within frameworks familiar to the scientists by taking advantage of existing seminar series. If the topics are presented openly and the questions are debated freely, without imposing solutions, this should prove fruitful and encourage further reflection. Other methods could be based on role-plays, which force participants to argue from a specific perspective (researcher, industrialist, security coordinator, publisher, military, and so on) and thus encourage them to engage with other views. ${ }^{36}$

Further lessons learned refer to the necessity to minimise the number of 'gatekeepers' by, wherever possible, making direct contact with the most appropriate office or department. Initial contact with potentially interested institutions should be made by a suitable communicator among the various offices concerned. For example, the response of universities or enterprises to

\footnotetext{
36 Dando and Rappert provide these lessons learned, principally based on their personal experience accumulated during the seminars held in various countries. The points were presented and discussed during the train-the-trainer session in the Spiez Laboratory, 21 August 2009. For teaching material, see also Rappert, B. 2009, The life science, biosecurity and dual-use research, available: http://projects.exeter.ac.uk/ codesofconduct/BiosecuritySeminar/Education/index.htm [viewed 5 March 2010].
} 
a first contact made by, say, the Federal Department of Defence (despite its competence and close involvement in BTWC affairs) is likely to be different from that to contact established perhaps through the Federal Office of Public Health.

\section{Possible Ways Forward}

Based on these lessons, the Swiss authorities are currently exploring possibilities for a follow-up. Admittedly, resources in this area are limited, but the seminars were carried out successfully with almost no (financial) resources. Though any further steps are likely to be similarly constrained, this does not necessarily mean a hindrance to future progress. For example, the analysis above indicates there is little need for changes in the legal framework - the relevant provisions already exist. Similarly, the educational system offers various platforms, and a substantial number of life-science researchers share at least implicitly the concerns of security practitioners, as the seminars confirmed. The existing awareness among first responders and security practitioners on national and cantonal levels provides a further important base. In summary, this indicates an existing potential, and illustrates numerous points to build on.

In practical terms, possible ways forward could include the following:

- Based on the initiative of various government offices such as the Federal Office for the Environment (FOEN) or the Federal Office of Public Health (FOPH), the recently established Biosafety Curriculum serves as a tool to harmonise the biosafety standards within Switzerland. This is implemented in courses for biosafety officers for safety levels one to three. ${ }^{37}$ Incorporating references to the debates on dual use and security into the courses would open the possibility of spreading the word directly into research facilities via the acting biosafety officers, and follow the principle of building on existing patterns of cooperation.

- Similarly, first responders could be made more aware of the issues through the existing patterns of shared competences and cooperation in the context of the national NBC-Protection Strategy. Via the Federal Commission for NBC Protection, thoughts on a conceptual extension of preventative measures with education could be introduced, while the Coordination Platform of the Cantons could serve as a gateway to cantonal authorities and their influence particularly on universities on the one hand, and first responders on the other.

37 B-Safe 2009, The Curriculum Biosafety - An initiative of the FOEN, the FOPH, the SUVA and the FECB, available: http://www.b-safe.ch/?mid=1379\&pid=1381\&lang_id=0\&lang_id=1 [viewed 22 January 2010]; and Federal Office for the Environment 2010, Biotechnology / Activities with genetically modified or pathogenic organisms in contained use, available: http://www.bafu.admin.ch/biotechnologie/01744/index.html?lang=en [viewed 22 January 2010]. 
- The militia system of the Swiss armed forces provides a further possibility. All armed forces personnel enjoy a basic education in NBC protection, particularly specialist troops such as the NBC troops or the medical corps, which are manned by civil experts working in comparable professional fields. The militia could be encouraged to actively introduce the topic into the civil workplace.

- Finally, education could be included as an element in a comprehensive political strategy on the national implementation of the BTWC. Such a strategy could serve as a guideline to the activities of authorities directly included in the BTWC process, and thus serve as a complementary element to the existing NBC-Protection Strategy (which focuses on operational aspects in the case of a crisis and includes no disarmament features, as discussed above).

\section{Concluding Remarks: Linking Life Sciences with Disarmament}

Serving as a report on work in progress, this chapter has described the implementation of an awareness-raising project on dual-use research in Switzerland as part of a continuous implementation of the BTWC. It has highlighted the lessons learned and possible ways forward. Switzerland still needs to define concrete lines of a long-term perspective. In addition, the importance of accounting for national particularities has been highlighted - the deliberately liberal environment limits government influence, and the federal structures generate an enormous number of actors and authorities. This often results in balanced and democratic solutions, but often requires timeconsuming processes, and the national implementation of the BTWC is no exception.

Despite the current lack of a universally applicable implementation model, this chapter has also shown that - as is probably the case elsewhere, too many of the prerequisites are already in place, making it easier to address some general concerns among life scientists. The fact that the final impulse was provided by a 'classical' disarmament regime did not hamper addressing actors and perspectives beyond the 'classical' disarmament horizon. Referring to recent successes in disarmament negotiations, John Borrie and Ashley Thornton extensively elaborated on the necessity to include diverse experts, and concluded that negotiating parties should think 'outside the box' and reach for experts far outside diplomatic circles. ${ }^{38}$ For Borrie and Thornton, this does not only mean the inclusion of international organisations, civil societies or victim associations, but also the establishment of diverse negotiation formats 
outside conventional diplomatic procedures. ${ }^{39}$ The findings of the present chapter imply that both negotiations and the implementation of disarmament regimes may require diversity. In the case of the BTWC and the prohibition of offensive uses of biological agents, such diversity could be provided by the deepened exchange between the life-science and disarmament communities. Indeed, classrooms where graduate students, fireguards, military intelligence and disarmament experts meet seem to be unusual. Yet whether implemented metaphorically or in reality, such classroom settings might contribute to the necessary diversity and formulation of new long-term approaches that help to create the missing link. 